\title{
Length of Stay of Psychiatric Admissions in a Tertiary Care Hospital
}

Madhur Basnet, ${ }^{1}$ Nidesh Sapkota, ${ }^{1}$ Suren Limbu, ${ }^{1}$ Dharanidhar Baral ${ }^{2}$

'Department of Psychiatry, B. P. Koirala Institute of Health Sciences, Dharan, Nepal, ${ }^{2}$ School of Public Health and Department of Community Medicine, B. P. Koirala Institute of Health Sciences, Dharan, Nepal.

\section{ABSTRACT}

Introduction: The length of stay among psychiatric in-patients is usually longer than that of others. Inpatient management is costly and longer length of stay can lead to catastrophic costs. We conducted this study to explore about the length of stay of psychiatric admissions and factors affecting it.

Methods: We collected the data of all the patients admitted to the psychiatric ward of B. P. Koirala Institute of Health Sciences from $1^{\text {st }}$ January 2007 to 31 $31^{\text {st }}$ December 2016 from the database of the medical records section after ethical approval. The sociodemographic and clinical variables were analyzed using SPSS 20.0 version. Length of stay more than 3 weeks was considered as long stay. Bivariate and multivariable logistic regression analyses were conducted to identify factors associated with length of stay.

Results: There were 3687 admissions during the study period. The average length of stay was $19.36( \pm 13.14)$ days. On logistic regression, the factors associated with shorter length of stay were: male gender $(\mathrm{aOR}=0.79$, 95\% CI: 0.68-0.93), being self employed $(\mathrm{aOR}=0.17,95 \% \mathrm{CI}: 0.12-0.22)$, homemakers $(\mathrm{aOR}=0.18,95 \% \mathrm{CI}$ : 0.14-0.24), farmers $(\mathrm{aOR}=0.20,95 \% \mathrm{CI}: 0.15-0.27)$ and students $(\mathrm{aOR}=0.23,95 \% \mathrm{CI}: 0.17-0.32)$. Similarly, factors associated with longer length of stay were: being from other Eastern Terai districts(aOR=1.37, 95\%CI: 1.11-1.70), other Eastern Hill districts $(\mathrm{aOR}=$ 1.68; 95\% CI: 1.29-2.20), diagnosis of schizophrenia and related disorders (aOR=4.01, 95\% CI: 1.34$12.0)$, having medical co-morbidity $(\mathrm{aOR}=3.47$; $95 \% \mathrm{CI}$ : $2.49-4.84)$ and being readmitted $(\mathrm{aOR}=1.23$, 95\% CI: 1.03-1.47).

Conclusions: There was significant association of length of stay with gender, age, address, occupation, diagnosis and readmission.

Keywords: length of hospital stay; mental illness; Nepal; psychiatric admission.

\section{INTRODUCTION}

There is a gross inadequacy of mental health services in Nepal. The WHO-AIMS report reported that there were only 17 community-based psychiatric inpatient units available in the country for a total of 1.00 beds per 100,000 population and treated 3.91 patients per 100,000 population with average length of stay(LoS) of 18.85 days. ${ }^{1}$ Increased LoS could lead to unavailability of already scarce beds to the needy besides leading to catastrophic costs. ${ }^{1}$ Various clinical and sociodemographic factors have been found to be associated with LoS. ${ }^{2-6}$

Psychosis, female gender and larger hospital size were associated with longer LoS while discharge against

Correspondence: Dr. Madhur Basnet, Department of Psychiatry, B. P. Koirala Institute of Health Sciences, Dharan, Nepal. Email madhurbasnet@gmail.com, Phone: +977-9852056415. 
medical advice, young or middle ages, being detained and being married were associated with shorter LoS. ${ }^{2}$ So, the study of LoS and factors associated with it can help the clinicians and policy makers to provide better services. This study was done to know about the LoS and factors associated with longer length of stay among patients admitted to the psychiatry ward.

\section{METHODS}

A cross-sectional study was carried out at B. P. Koirala Institute of Health Sciences (BPKIHS). After the ethical approval was taken on 27 November 2017 from the Institutional Review Committee (IRC) of BPKIHS, we extracted the data regarding the sociodemographic and clinical variables of all the patients admitted to the psychiatry ward of BPKIHS from 1st January 2007 to 31st December 2016. All precautions were taken to conceal the identification of the patients in the data. Those patients who had incomplete data were excluded. The psychiatric diagnosis were made according to ICD10 Classification of Mental and Behavioural DisordersClinical Description and Diagnostic Guidelines (ICD$10 \mathrm{CDDG}^{7}$ criteria by consultant psychiatrists after adequate detail work up. The medical record section of the institute keeps a well maintained electronic database with records of all in-patients according to the ICD-10 diagnostic categories. We included age, gender, address, occupation, religion, year of admission, month of admission, disease category, outcome at discharge and readmission as the independent variables and the LoS as the outcome variable. We considered $>21$ days LoS as longer LoS. As B. P. Koirala Institute of Health Sciences had a very large catchment area including whole of the Eastern Development Region, we categorized address according to approximate proximity to BPKIHS as: Sunsari District, surrounding districts of Sunsari(Dhankuta, Morang, Saptari and Udaypur), Other Eastern Terai Districts (Jhapa and Siraha) and other Eastern Hill Districts (Taplejung, Panchthar, Ilam, Sankhuwasabha, Terahthum, Bhojpur, Khotang and Solukhumbu). This was done as literature have shown the role of proximity to the service in mental health service utilization. ${ }^{8-10}$ The data were entered into MS Excel and analysed using the SPSS version 20.0. For descriptive statistics, percentage, mean, range and standard deviation were calculated.We used bivariate and multiple logistic regression analysis to find the strength of association of LoS with variables of interest and adjusted Odds Ratio (aOR) were calculated with $95 \%$ confidence interval $(\mathrm{Cl})$. The difference was considered significant at $\mathrm{P}<0.05$. were cancelled the same day being wrong admissions and ten admissions were cancelled by the patient/ patient party the same day and so were removed from the analysis. Psychiatric diagnoses were missing in $61(1.7 \%)$ admissions, probably due to error in data entry and these cases were not included when analysing LoS according to diagnosis. There were 1504 $(40.8 \%)$ female and $2183(59.2 \%)$ male admissions. The mean age of the patients was 32.4 years $( \pm 12.6)$ with age range from 4-92 years. The details of findings of multivariable logistic regression analysis for factors associated with long LoS has been presented in Table 1. Highest number of admissions were recorded from Sunsari distri which was 1161 (31.4\%) alone followed by surrounding districts of Sunsari $31.1 \%$, other Eastern Terai Districts was $26.1 \%$ and other Eastern Hill districts was $11.3 \%$ depicting significant effect of proximity to the hospital in the rate of admission. Only 347 (9.4\%) cases were unemployed. The average admissions were highest $375(10.2 \%)$ in March and lowest $243(6.6 \%)$ in September.

Among the 3626 cases with recorded psychiatric diagnoses, 3406 cases had single diagnoses and 220 had mixed diagnoses. Of those with single diagnosis, mood disorders were the commonest diagnosis in 1701 $(49.9 \%)$ followed by mental and behavioural disorders due to psychoactive substance use was 781 (22.9\%), schizophrenia and related disorders was 745 (22.5\%) and others. There were 2730 (74\%) single admission and $957(26 \%)$ readmissions. The outcome at the time of discharge was good with 3392 (92\%) discharged in improved state, 139 (3.8\%) Left Against Medical Advice (LAMA), 119 (3.2\%) absconded, 34 (0.9\%) and only three $(0.1 \%)$ deaths in ten years.

The mean LoS was $19.4( \pm 13.1)$ days with range of 1-124 days,median of 16 days and mode of 14 days. The bed occupancy rate was $65.2 \%$. The average LoS was highest for those from other Eastern hill districts $(21.4 \pm 13.4$ days) and least for Sunsari $(18.3 \pm 13.3$ days). The mean LoS was highest $(21.8 \pm 15.5$ days $)$ in May and lowest $(17.7 \pm 11.2$ days) in March (Figure 2). The mean LoS was highest for schizophrenia and related disorders $(20.9 \pm 14.7$ days $)$ and least for organic mental disorders $(12.9 \pm 8.4$ days $)$.

In multivariable logistic regression (Table 1) there was significant association of LoS with age, gender, address, occupation, diagnosis of schizophrenia, presence of medical co-morbidity and readmission.

\section{RESULTS}

There were a total of 3699 admissions of which two 
Basnet et al. Length of Stay of Psychiatric Admissions in a Tertiary Care Hospital

\begin{tabular}{|c|c|c|c|c|c|c|}
\hline Variables & Categories & $\begin{array}{l}\text { Length of Stay } \\
1-21 \text { days }(\%)\end{array}$ & $\begin{array}{l}>21 \text { d a y s } \\
(\%)\end{array}$ & Total & $\begin{array}{l}\text { aOR } \\
(95 \% \mathrm{Cl}) *\end{array}$ & $P$ value \\
\hline Age & Mean Age & $\begin{array}{l}33.17 \\
( \pm 12.66)\end{array}$ & $\begin{array}{l}30.89 \\
( \pm 12.24)\end{array}$ & 3687 & $\begin{array}{l}0.99 \\
(0.98-0.99)\end{array}$ & 0.000 \\
\hline \multirow[b]{2}{*}{ Gender } & Female & $956(63.6)$ & $548(36.4)$ & 1504 & 1 & \\
\hline & Male & $1539(70.5)$ & $644(29.5)$ & 2183 & $\begin{array}{l}0.79 \\
(0.68-0.93)\end{array}$ & 0.005 \\
\hline \multirow{4}{*}{ Address } & Sunsari & $839(72.4)$ & $320(27.6)$ & 1159 & 1 & \\
\hline & Surrounding Districts of Sunsari & $771(67.2)$ & $376(32.8)$ & 1147 & $\begin{array}{l}1.21 \\
(0.99-1.49)\end{array}$ & 0.061 \\
\hline & Other Eastern Terai Districts & $636(66.0)$ & $328(34)$ & 964 & $\begin{array}{l}1.37 \\
(1.11-1.70)\end{array}$ & 0.003 \\
\hline & Other Eastern Hill Districts & $249(59.7)$ & $168(40.3)$ & 417 & $\begin{array}{l}1.68 \\
(1.29-2.20)\end{array}$ & 0.000 \\
\hline \multirow{6}{*}{ Occupation } & Unemployed & $117(32.4)$ & $244(67.6)$ & 361 & 1 & \\
\hline & Self Employed & $704(75.1)$ & $234(24.9)$ & 938 & $\begin{array}{l}0.17 \\
(0.12-0.22)\end{array}$ & 0.000 \\
\hline & Service Holder & $44(29.9)$ & $103(70.1)$ & 147 & $\begin{array}{l}1.13 \\
(0.72-1.76)\end{array}$ & 0.603 \\
\hline & Homemaker & 792 (74.9) & $265(25.1)$ & 1057 & $\begin{array}{l}0.18 \\
(0.14-0.24)\end{array}$ & 0.000 \\
\hline & Farmer & $423(72.9)$ & $157(27.1)$ & 580 & $\begin{array}{l}0.20 \\
(0.15-0.27)\end{array}$ & 0.000 \\
\hline & Student & $415(68.7)$ & 189 (31.3) & 604 & $\begin{array}{l}0.23 \\
(0.17-0.32)\end{array}$ & 0.000 \\
\hline \multirow{8}{*}{ Diagnosis } & Organic Mental Disorders & $30(88.2)$ & $4(11.8)$ & 34 & 1 & \\
\hline & $\begin{array}{l}\text { Mental and behavioural disorders } \\
\text { due to psychoactive substance } \\
\text { use }\end{array}$ & $528(67.6)$ & $253(32.4)$ & 781 & $\begin{array}{l}2.96 \\
(0.99-8.87)\end{array}$ & 0.053 \\
\hline & $\begin{array}{l}\text { Schizophrenia, schizotypal and } \\
\text { delusional disorders }\end{array}$ & $474(63.6)$ & $271(36.4)$ & 745 & $\begin{array}{l}4.01 \\
(1.34-12.00)\end{array}$ & 0.013 \\
\hline & Mood Disorders & $1235(72.6)$ & $466(27.4)$ & 1701 & $\begin{array}{l}2.81 \\
(0.94-8.36)\end{array}$ & 0.063 \\
\hline & $\begin{array}{l}\text { Neurotic, stress-related and } \\
\text { somatoform disorders }\end{array}$ & $66(73.3)$ & $24(21.7)$ & 90 & $\begin{array}{l}2.54 \\
(0.77-8.37)\end{array}$ & 0.126 \\
\hline & Others & $15(68.2)$ & $7(31.8)$ & 22 & $\begin{array}{l}2.97 \\
(0.70-12.64)\end{array}$ & 0.141 \\
\hline & Suicide & $22(66.7)$ & $11(33.3)$ & 33 & $\begin{array}{l}0.95 \\
(0.24-3.75)\end{array}$ & 0.942 \\
\hline & Mixed Diagnoses & & & & & \\
\hline \multirow{3}{*}{$\begin{array}{l}\text { Medical } \\
\text { Co- } \\
\text { morbidity }\end{array}$} & No & $2332(69.3)$ & $\begin{array}{llll}1 & 0 & 3 & 5 \\
(30.7) & \end{array}$ & 3367 & 1 & \\
\hline & Yes & $163(50.9)$ & $157(49.1)$ & 320 & $\begin{array}{l}3.47 \\
(2.49-4.84)\end{array}$ & 0.000 \\
\hline & No & 1883 (69.0) & 847 (31.0) & 2730 & 1 & \\
\hline Readmission & Yes & 612 (63.9) & $345(36.1)$ & 957 & $\begin{array}{l}1.23 \\
(1.03-1.47)\end{array}$ & 0.020 \\
\hline
\end{tabular}

* The constant in the model $=0.439$. 

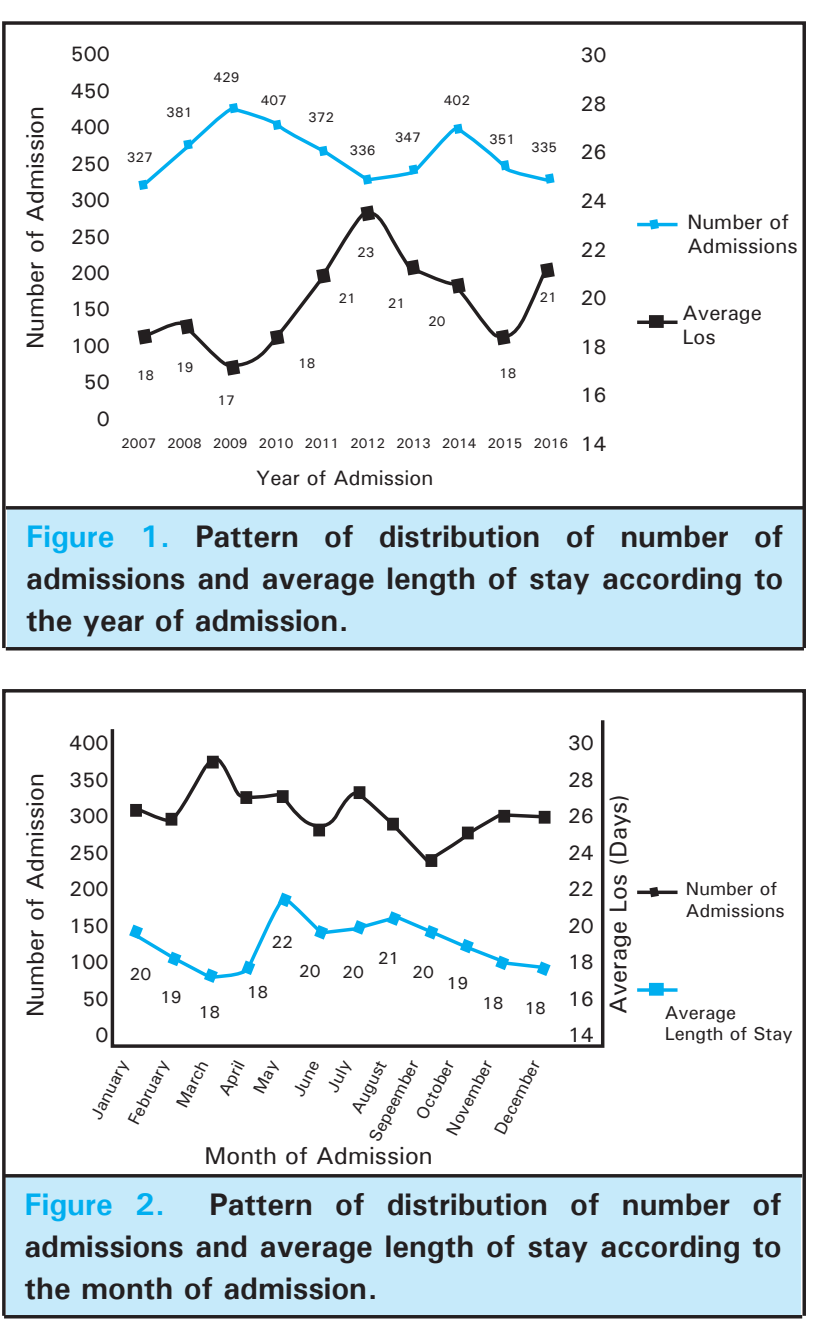

\section{DISCUSSION}

In multivariable logistic regression model, there was significant association of age, gender, address, occupation, diagnosis, presence of medical comorbidity and readmission with longer LoS. The overall model was significant $(P=0.000)$ with overall prediction of $73 \%$ of the variance, -2 Log likelihood 3717.792, chi-square 399.567 and $d f=18$. There were disproportionately high admissions from Sunsari district $(31.4 \%)$ while it only constituted $13 \%$ of the total population of Eastern Development region. ${ }^{11}$ One of the reasons for this finding could be to ease of access to the facility. Several studies have shown that increase in distance decreases the likelihood of service utilization in mental health. ${ }^{8-10,12-14}$ Similarly, there was significant association of proximity to hospital with LoS, those from same and nearby districts had shorter LoS as compared to others. In our clinical experience, those from nearby places, who could follow up regularly to OPD are discharged earlier as compared to those from faraway places who could have difficulty in following up regularly. This could be one of the reasons and other reasons need to be explored further. The finding of maximum LoS in May in our study is similar to the findings by $G$. Singh et al in India who reported high LoS in summer (May-July). ${ }^{15}$ The higher odds of females having longer LoS than females was reported in study by Tulloch et al as well. ${ }^{2}$ However reported that although there was higher median LoS in females than males, there was no statistically significant difference. ${ }^{16}$ The diagnosis of schizophrenia and related disorders was significantly associated with higher odd of longer LoS as compared to those with organic mental disorders. Addisu et al reported that patients with major depressive disorder(aOR $=0.51 ; 95 \%$ $\mathrm{Cl}$ : $0.32-0.81$ ) and brief psychotic disorder $(\mathrm{aOR}=$ $0.52 ; 95 \% \mathrm{Cl}: 0.33-0.84)$ had shorter hospital stays compared to those with a diagnosis of schizophrenia and other psychotic disorders. ${ }^{3}$ Newman et al also reported having diagnosis of psychosis, being male and unemployed/retired were associated with longer LoS compared to reference groups. ${ }^{17}$ Presence of medical co-morbidity not only demands for better co-ordination among different treating teams but also hinders in more aggressive in-patient treatment as these patients are likely to have more side effects with psychotropics. They are also more likely to have more severe illness. All these factors could lead to prolonged stay in patients with medical co-morbidity. Similarly, those with more readmissions are more likely to have more severe illness and so require longer hospital stay. Stevens et al also have reported significant association of longer average LoS with previous one to three admissions as compared to first admission. ${ }^{16}$

Though different factors variables have been found to have significant association on LoS, outcome and readmission, the causal association could not be established as it's a retrospective study. Many of the sociodemographic variables like socioeconomic condition, education, distance from the facility and clinical variables like severity of illness also have been found to have significant effect in LoS in other studies but these were missing in our record and so could not be studied.

\section{CONCLUSIONS}

There were total of 3687 admissions during the study period. The mean LoS was $19.4( \pm 13.1)$ days with range of 1-124 days. There were disproportionately high admissions from Sunsari District indicating strong association of use of psychiatric in-patient services with proximity to services. So, there is great need for expanding the in-patient services to other parts of Eastern Nepal as well. Similarly, LoS was significantly associated with age, gender, address, occupation, diagnosis, presence of medical co-morbidity and readmission. The knowledge of the factors associated 
with longer LoS could inform the policy makers and hospital managers and clinicians on better care to the patients admitted to psychiatry ward. Unemployment was associated with higher LoS compared to others and so, providing opportunities for employment might help reduce the LoS and associated morbidity. Similarly, those with medical co-morbidity had longer LoS and so, more co-ordinated and comprehensive care with better management of medical conditions could help reduce the LoS.

\section{ACKNOWLEDGEMENTS}

The authors would like to thank the Medical Records Section of B. P. Koirala Institute of Health Sciences for providing us with the needed data and the department of Psychiatry B. P. Koirala Institute of Health Sciences for helping us logistically while carrying out the study.

\section{Conflict of Interest: None.}

\section{REFERENCES}

1. WHO (World Health Organization). WHO-AIMS report on mental health system in Nepal [Internet]. Kathmandu: World Health Organization. 2006 [cited 2018 Mar 1]. Available from: http://www.who.int/mental_health/evidence/ nepal_who_aims_report.pdf. [․ㅏll Text]

2. Tulloch AD, Fearon P, David AS. Length of stay of general psychiatric inpatients in the United States: systematic Review. Adm Policy Ment Heal Ment Health. 2011 May;38(3):155-68. [PubMed]

3. Addisu F, Wondafrash M, Chemali Z, Dejene T, Tesfaye M. Length of stay of psychiatric admissions in a general hospital in Ethiopia: a retrospective study. Int J Ment Health Syst. 2015;9(1):13. [PMC]

4. Zhang J, Harvey C, Andrew C. Factors Associated with length of stay and the risk of readmission in an acute psychiatric inpatient facility: a retrospective Study. Aust N Z J. Psychiatry. 2011 Jul;45(7):578-5. [PubMed]

5. Auffarth I, Busse R, Dietrich D, Emrich H. Length of psychiatric inpatient stay: Comparison of mental health care outlining a case mix from a hospital in Germany and the United States of America. Ger J Psychiatry. 2008;11(2):40-4. [Full Text]

6. Chung $\mathrm{W}$, Oh SM, Suh T, Lee YM, Oh BH, Yoon CW. Determinants of length of stay for psychiatric inpatients: Analysis of a national database covering the entire Korean elderly population. Health Policy. 2010;94(2):120-8. [Pub Med | DOI]

7. WHO. The International Classification of Diseases: Classification of Mental and Behavioural Disorders: Clinical Descriptions and Diagnostic Guidelines [Internet]. Norman Sartorius, editor. Geneva: WHO; 1992 [cited 2018 Mar 20] 362 p. Available from: http://apps.who.int/iris/bitstream/ 10665/37958/8/9241544228_eng.pdf. [Full Text]

8. Stulz N, Pichler EM, Kawohl W, Hepp U. The gravitational force of mental health services: distance decay effects in a rural Swiss service area. BMC Health Serv Res. 2018;18(1):81. [PMC]
9. Zulian G, Donisi V, Secco G, Pertile R, Tansella M, Amaddeo F. How are caseload and service utilisation of psychiatric services influenced by distance? A geographical approach to the study of community-based mental health services. Soc Psychiatry Psychiatr Epidemiol. 2011;46(9):881-91. [PubMed]

10. Packness A, Waldorff FB, Christensen R dePont, Hastrup LH, Simonsen E, et al. Impact of socioeconomic position and distance on mental health care utilization: a nationwide Danish follow-up study. Soc Psychiatry Psychiatr Epidemiol. 2017 Nov 28;52(11):1405-13. [PubMed]

11. Central Bureau of Statistics, National Planning Commission G of N. National Population and Housing Census 2011 (National Report) [Internet]. Kathmandu, Nepal; 2012 [cited 2018 Mar 12]. Available from: http://cbs.gov.np/image/ data/Population/National Report/National Report.pdf. [Full Text]

12. Bürgy R, Häfner-Ranabauer W. Utilization of the psychiatric emergency service in Mannheim: Ecological and distance-related aspects. Soc Psychiatry Psychiatr Epidemiol. 1998 Nov;33(11):558-67. [ubMed]

13. McCarthy JF, Valenstein M, Zivin K, Zeber JE, Kilbourne AM. Access-related measures and out-of-system utilization among veterans with bipolar disorder. Psychiatr Serv. 2010 Oct;61(10):1035-8. [PubMed]

14. Sohler KB, Thompson JD. Jarvis' law and the planning of mental health services. Influence of accessibility, poverty, and urbanization on first admissions to Connecticut State hospitals. Public Health Rep. 1970 Jun;85(6):503-10. [PMC]

15. Singh GP, Chavan BS, Arun P, Sidana A. Seasonal pattern of psychiatry service utilization in a tertiary care hospital. Indian J Psychiatry. 2007 Apr;49(2):91-5. [PubMed]

16. Stevens A, Hammer K, Buchkremer G. A statistical mode for length of psychiatric in-patient treatment and an analysis of contributing factors. Acta Psychiatr Scand [Internet]. 2001 Mar;103(3):203-11. [PubMed]

17. Newman L, Harris V, Evans LJ, Beck A. Factors Associated with Length of Stay in Psychiatric Inpatient Services in London, UK. Psychiatr Q. 2018 Mar;89(1):33-43. [PubMed] 